\title{
Silvano Falcioni, Il politico sabotato. Su Georges
}

Bataille

\section{Gian Luigi Di Bernardini}

\section{Q OpenEdition}

1 Journals

\section{Edizione digitale}

URL: http://journals.openedition.org/studifrancesi/5758

DOI: 10.4000/studifrancesi.5758

ISSN: 2421-5856

\section{Editore}

Rosenberg \& Sellier

\section{Edizione cartacea}

Data di pubblicazione: 1 septembre 2011

Paginazione: 453

ISSN: 0039-2944

\section{Notizia bibliografica digitale}

Gian Luigi Di Bernardini, «Silvano Falcioni, II politico sabotato. Su Georges Bataille», Studi Francesi [Online], 164 (LV | II) | 2011, online dal 30 novembre 2015, consultato il 13 janvier 2021. URL: http:// journals.openedition.org/studifrancesi/5758; DOI: https://doi.org/10.4000/studifrancesi.5758

Questo documento è stato generato automaticamente il 13 janvier 2021.

\section{(c) (i) (9)}

Studi Francesi è distribuita con Licenza Creative Commons Attribuzione - Non commerciale - Non opere derivate 4.0 Internazionale. 


\title{
Silvano Falcioni, Il politico sabotato. Su Georges Bataille
}

\author{
Gian Luigi Di Bernardini
}

\section{NOTIZIA}

SILVANO FALCIONI, Il politico sabotato. Su Georges Bataille, Milano, Jaca Book, 2009, 147 pp.

1 Il politico sabotato attira l'attenzione sulla complessa figura di Georges Bataille la cui parabola esistenziale e scrittoria si colloca intorno alla metà del xx secolo. Dopo aver ricordato nell'introduzione (Fuori cornice, pp.13-19) il complesso rapporto che legava Bataille a Maurice Blanchot, Falcioni propone un'opera dall'evidente impostazione filosofica, nei termini, tuttavia, di una filosofia contemporanea che non può più prescindere dal supporto linguistico che ne ospita la riflessione. Tali scelte spiegano il carattere semantico che spesso assume l'analisi del corpus costituito dai testi raccolti nella rivista «Documents», da Bataille fondata e che costituisce il nucleo centrale della prima delle due sezioni di cui si compone il saggio (Il problema della «dépense», pp. 21-82). La nozione annunciata tra virgolette nel titolo viene definita tramite una serie di opposizioni di cui la principale è quella che contrappone dépense a utilità. In altri termini, Bataille polemizza radicalmente contro ogni forma di società fondata sui principi dell'utilità, della conservazione, del mantenimento di sé, dell'accumulo e, come conseguenza, della centralità accordata al futuro. A tali valori l'autore contrappone un progetto di comunità fondata sul costante dono di sé e sull'istante presente. È in questo senso che va inteso, quindi, il senso dell'aggettivo contenuto nel titolo del saggio, il quale va riferito alle posizioni di Bataille nel dibattito politico coevo e che tende a "sabotare", appunto, ogni possibile forma di potere, sia esso di natura borghese od operaia.

2 La seconda parte (Dalla «dépense» alla comunità segreta, pp. 83-136) verte sull'esperienza della rivista «Acéphale», fondata nel 1936 da Bataille insieme ad una comunità segreta omonima su cui, tuttavia, non si dispone di una documentazione sufficientemente 
ampia da poter giungere ad una qualche convinzione fondata su di essa. Bataille auspica, in sostanza, la liberazione di tutti gli elementi eterogenei che la strutturazione conservatrice della società tende ad appiattire, ad omologare appunto. Lo strumento atto a tale scopo è identificato nella costruzione di un piano mitologico radicalmente alternativo a quello costruito dai totalitarismi di ogni segno. Si scorge, peraltro, la chiara polemica di Bataille contro la manipolazione a fini ideologici delle posizioni filosofiche di Nietzsche operata dal Nazismo.

Dopo il Congedo (pp. 137-142) si trova un indice dei nomi (pp. 145-147). 